\title{
Male krill grow fast and die young
}

\author{
So Kawaguchi ${ }^{1, *}$, Luke A. Finley ${ }^{1,2}$, Simon Jarman ${ }^{1}$, Steven G. Candy ${ }^{1}$, \\ Robin M. Ross ${ }^{3}$, Langdon B. Quetin ${ }^{3}$, Volker Siegel ${ }^{4}$, Wayne Trivelpiece ${ }^{5}$, \\ Mikio Naganobu ${ }^{6}$, Stephen Nicol $^{1}$
}

\author{
${ }^{1}$ Australian Antarctic Division, Department of the Environment and Water Resources, 203 Channel Highway, Kingston, \\ Tasmania 7050, Australia \\ ${ }^{2}$ Department of Zoology, The University of Melbourne, Victoria 3010, Australia \\ ${ }^{3}$ Marine Science Institute, University of California at Santa Barbara, Santa Barbara, California 93106-6150, USA \\ ${ }^{4}$ Seafisheries Research Institute, Palmaille 9, 22767 Hamburg, Germany \\ ${ }^{5}$ US AMLR Program, Southwest Fisheries Science Center, 8604 La Jolla Shores Drive, La Jolla, California 92037, USA \\ ${ }^{6}$ National Research Institute of Far Seas Fisheries, 2-12-4, Fukuura, Kanazawa-ku, Yokohama, Kanagawa 236-8648, Japan
}

\begin{abstract}
The size-differentiated sex ratio (proportion of males, PM) of Antarctic krill Euphausia superba was examined with an extensive dataset derived from scientific surveys in the Indian Ocean sector and the southwest Atlantic sector, and from the krill fishery in the Southern Ocean. The percentage of males in size classes of adult krill was generally high in krill of 30 to $35 \mathrm{~mm}$ total length, always low in 38 to $42 \mathrm{~mm}$ krill, sometimes showed higher values in 45 to $50 \mathrm{~mm}$ krill, but always decreased in the largest krill (>50 mm). This pattern was reproduced by a model simulation that assumed faster growth and a shorter lifespan for males when compared to females. These results suggest that the numbers of males should decline with time unless new recruits enter the population. Indeed, interannual variations in PM from the field (net collected data and penguin diet data) showed a decline in the proportion of males when several years of low recruitment followed a recruitment pulse. These results lead us to conclude that male krill grow faster and have a shorter lifespan than females in the natural environment.
\end{abstract}

KEY WORDS: Euphausia superba $\cdot$ Sex ratio $\cdot$ Proportion of males $\cdot$ Lifespan $\cdot$ Mortality $\cdot$ Longevity Recruitment $\cdot$ Length-frequency distribution

\section{INTRODUCTION}

Antarctic krill Euphausia superba is the main prey species of baleen whales, seals, and penguins in the Southern Ocean. Consequently, issues surrounding their biomass and production have been the subject of considerable debate, particularly because they have been commercially harvested for $>30$ yr (e.g. Rosenberg et al. 1986, Loeb et al. 1997, Nicol \& Endo 1999, Nicol et al. 2000, Watkins et al. 2004). Recent suggestions of significant declines in krill density and possible recruitment failures in the South Atlantic associated with reductions in sea-ice area (Loeb et al. 1997, Atkinson et al. 2004) emphasize the urgency of adopting appropriate management measures for the harvesting of krill stocks for the health of the entire Antarctic marine ecosystem. Understanding the population dynamics of Antarctic krill is key to designing a management scheme, and that requires knowledge of growth and mortality during its lifespan.

Since the age of krill is hard to measure directly (Nicol 2000), total body length has generally been used as the basic indicator of age, though considerable complications arise because krill are thought to shrink during winter (Nicol 2000). None-the-less, total length is still used to examine krill population dynamics (Siegel \& Nicol 2000) and to derive an index of recruitment used in the management of the krill fishery (de la Mare 1994). Length-at-age is determined by growth rate, and the general assumption has been that males 
and females grow at similar rates. Population trends have therefore been followed using pooled data from both sexes.

Earlier studies of Antarctic krill highlight the topics of sex ratios, sex-differentiated growth, development, and mortality rate. Bargmann (1945; their Fig. 3) demonstrated a consistently smaller size of females compared to the males in their growth trajectory. Further, Marr (1962) observed dominance of males in swarms becoming more pronounced as development proceeds, but their disappearance after mating. He suggested that when the males have transferred their spermatophores they begin to die off earlier than the females (Marr 1962). Although these early observations are a critical issue for Antarctic krill's population dynamics, it has somehow been overlooked in recent years and has never been corroborated.

In the present study, we revisit the sex ratio issue in Antarctic krill by examining their growth rates and mortality using a combination of recent comprehensive datasets, including experimental results, field data, fishery data, and modeling. We discuss the implications of these results for ecosystem-based management.

\section{MATERIALS AND METHODS}

The overall analysis consisted of 2 parts. First, krill Euphausia superba sex ratio across length classes was examined using an extensive field survey dataset. Second, model simulation was performed to explore the model structure and parameter settings that best explain the trends observed from the field.

Surveys. Data came from multiple sampling programs from a range of years and regions (Table 1). Three of the surveys were conducted off east Antarctica: (1) Baseline Research on Oceanography, Krill, and the Environment (BROKE); (2) Krill Availability, Community Trophodynamics and AMISOR Surveys (KACTAS); and (3) Krill Acoustic Oceanography Survey (KAOS). West of the Antarctic Peninsula (excluding Elephant Island) multi- year sampling programs have been conducted by the Palmer Long-Term Ecological Research (Palmer LTER) program (USA) that has sampled in each summer since 1993 (Smith et al. 1995) and the German Antarctic Marine Resources (GAMLR) expeditions carried out in 8 yr between 1978 and 2000. Krill from the krill fishery in the Scotia Sea were collected daily by a Japanese national observer onboard during the 1999/2000 fishing season. Penguin diet samples were collected at the Cape Shirreff field camp of the US-AMLR (United States Antarctic Marine Living Resources) program on Livingston Island in the South Shetland Islands during austral summers between 1998 and 2005.

Krill sampling and sex identification. Net sampling of krill was performed by double oblique tows, either from the surface to $200 \mathrm{~m}$ with an RMT-8 (Barker et al. 1973) (BROKE, KACTAS, KAOS, and GAMLR) or from the surface to $120 \mathrm{~m}$ with a $2 \mathrm{~m}$ square fixed frame net (Palmer LTER). Krill from the fishery were taken from commercial hauls. Krill were measured and staged (Makarov \& Denys 1980). Measurement of total length was done using the standardized AT measurement (anterior edge of eye to tip of telson) for GAMLR and fishery samples, and the S1 measurement (tip of rostrum to end of uropod) for the rest of the surveys (Morris et al. 1988). Stage classification methodology was consistent between all surveys including samples from the fishery (fishery samples were processed at the National Research Institute of Far Seas Fisheries Japan). Internal features (i.e. presence of a primitive ovary or uncoiled vas deferens) were not used. Sex was assigned to all individuals for stages of subadults and above. Individuals without any external characteristics were assigned as juveniles and excluded from sex ratio analysis of the net samples. Potential bias in proportion of males (PM) by excluding juveniles (which might have different PM to subadults and adults of the same length class) was also evaluated by examining proportion of juveniles in each size bin.

For sex ratio calculations, krill length-frequency distributions (LFDs) were binned by $2 \mathrm{~mm}$ intervals and PM values were calculated for each length class. The

Table 1. Sources of data. Survey abbreviations, see 'Materials and methods - Surveys'

\begin{tabular}{|lll|}
\hline Name & Dates & Location \\
\hline BROKE (Australia) & 29 Jan-22 Mar 1996 & $\sim 63-67^{\circ} \mathrm{S}, 80-150^{\circ} \mathrm{E}$ \\
KACTAS (Australia) & 1 Jan-9 Mar 2001 & $\sim 66-67^{\circ} \mathrm{S}, 62-64.5^{\circ} \mathrm{E}(60 \times 60 \mathrm{n}$ mile box off Mawson Station) \\
KAOS (Australia) & 3 Jan-18 Mar 2003 & \\
Palmer LTER (USA) & Jan 1993-Jan 2003 & $\sim 64-69^{\circ} \mathrm{S}, 62-76^{\circ} \mathrm{W}(400 \mathrm{~km}$ alongshore $\times 200 \mathrm{~km}$ on/offshore $)$ \\
GAMLR & $1978,1981-1982,1985$, & Antarctic Peninsula area \\
Krill fishery (Japanese national & $1988,1990,1994,2000$ & \\
$\begin{array}{l}\text { observer) } \\
\text { US-AMLR penguin diet samples }\end{array}$ & Summers 1998-2005 & Livingston Island $\left(62^{\circ} 28^{\prime} \mathrm{S}_{,}, 60^{\circ} 46^{\prime} \mathrm{W}\right)$ \\
\hline
\end{tabular}


reason for using $2 \mathrm{~mm}$ bins was to avoid (as far as is possible) small sample sizes in each size bin towards the higher and lower ends of their size distribution. The PM for an entire season was derived by dividing the sum of male density estimates by the sum of male and female density estimates.

Sex of krill in penguin diets was determined from the shape of the carapace (Hill 1990). Diet samples were obtained by stomach flushing following the CCAMLR (Commission for the Conservation of Antarctic Marine Living Resources) ecosystem monitoring program standard methods (CCAMLR 2003).

Model simulation of growth and LFD. Daily change in krill length can be expressed as:

$$
L_{t+1}=L_{t}+G\left(L_{t}\right)
$$

where $L_{t}$ is length of krill on Day $t$, and $G\left(L_{t}\right)$ is the daily growth of an $L_{t}$ sized animal. Kawaguchi et al. (2006) predicted daily growth of male and female krill, and demonstrated that $G\left(L_{t}\right)$ varies with month and sex, as well as with animal size class. By using the daily growth rate values of 20,30,40, and $50 \mathrm{~mm}$ sized animals (given in Table 2 of Kawaguchi et al. 2006), simple linear regression functions of daily growth as a function of size were derived for each month of the growth season (December to April) (Table 2), with growth outside this period assumed to be zero. Using a starting mean length at Age 1 of $28 \mathrm{~mm}$, the estimated mean length for Ages 1 to 5 were obtained by accumulating growth increments using Eq. (1) with month and sex-specific daily growth rates, and the integer ages were specified, nominally, as the age on 1 May in each year.

The von Bertalanffy (VB) growth model was fitted to the set of mean lengths-at-age, with different combinations of sex-specific parameters. The VB growth model for total length $L$ and age $A$ is given by:

$$
L=L_{\infty}\left\{1-\exp \left[-\kappa\left(A-t_{0}\right)\right]\right\}
$$

where the parameters are the upper asymptote $L_{\infty}$, the location parameter $t_{0}$, and the rate parameter $\kappa$. Three parameterisations were fitted using ordinary least squares: (1) all 3 parameters sex specific, denoted $\mathrm{VB}\left(s, L_{\infty}, \kappa, t_{0}\right),(2)$ no parameters sex specific, denoted $\mathrm{VB}(\mathrm{M}+\mathrm{F})$, and (3) sex-specific $\kappa$ parameters, denoted $\operatorname{VB}(s, \kappa)$. Due to the limited nature of the data used for fitting with the mean length estimates themselves, formal likelihood ratio testing of the above 3 versions of the VB model was not carried out, instead the most appropriate model was judged by how reasonable the fitted VB curves and their parameters appeared to be.
LFDs of males and females for each age class were simulated using predicted mean lengths for Ages 1 to 7 from the fitted VB model and random draws for 10000 ind. for each age class from a normal distribution with the above predicted means and a separate, pre-specified SD for each age class. Predicted number of krill dying by the end of each age class (i.e. Ages 2 to 7 ) were removed from the 10000 random samples (i.e. 10000 individual krill were assumed at the start of the Age 1 age class). A base-case simple exponential decay survival model was used to determine numbers retained in each age class so that:

$$
N_{A+Y}=N_{A} \exp \left(-M_{S} Y\right)
$$

where $N_{A}$ is the number surviving at Age $A\left(N_{1}=10000\right)$ $M$ is the instantaneous mortality rate parameter that can vary by sex $s$ (M: males, F: females) and $y$ is the number of years projected. As well as varying $M$ between sexes, the assumed lifespan could be varied by assuming that all individuals for a given sex die after the last specified age class, with the number of age classes allowed to vary by sex. Alternatively, an accelerated mortality model was also implemented, whereby, from Age $A_{\lambda}$, male mortality could be accelerated by using a value of the parameter $\lambda$ that is $>0$, where:

$$
\begin{array}{llrl}
N_{A+y} & =N_{A} \exp \left(-M_{M} y\right), & & A+y \leq A_{\lambda} \\
N_{A+y} & =N_{A} \exp \left[-\left(M_{M}+\lambda\right) y\right], & & A \geq A_{\lambda}
\end{array}
$$

The empirical LFD was obtained using $1 \mathrm{~mm}$ length bins from 19 to $70 \mathrm{~mm}$, and the ratio of males to the sum of males and females for each bin was determined and is denoted the 'sex ratio (PM)'. The simulation was replicated 1000 times to allow quantiles of the empirical sex ratio distribution for each length bin to be determined. Median, upper, and lower $95 \%$ quantiles were used. An extra level of stochastic variation was permitted in addition to that obtained by the random draws from the agespecific length distributions for each sex. This extra stochastic variation was implemented across the 1000 
replicates and consisted of allowing either or both $M_{F}$ and $M_{M}$ to vary independently between replicates (and each other) as lognormal random variates about the specified mean values for each parameter, with prespecified coefficient of variation for each lognormal distribution set to 0.2 for all simulations for both males and females. The male-to-female mortality rate (MFMR) ratio was calculated simply as $M_{M} / M_{F}$.

The simulation was programmed using the $\mathrm{R}$ language (www.r-project.org/); the user guide and script are in Appendices 1 \& 2 (available at www.int-res.com/ articles/suppl/m345p199_app/).

\section{RESULTS}

\section{Field data}

Trends in PM from scientific surveys and fishery

Based on krill Euphausia superba LFD data from all major cruises in the Indian Ocean conducted by the Australian Antarctic Division from 1996 to 2003, PM was consistently high in the smallest adult size class (30 to $35 \mathrm{~mm}$ ) (Fig. 1). The PM was always low in medium sized krill (38 to $42 \mathrm{~mm}$ ), but showed higher values in larger krill ( 45 to $50 \mathrm{~mm}$ ), and the values again decreased in the largest animals. Although more variable, the same trends were also observed for average plots of PM from scientific net samples from the Antarctic Peninsula area (Palmer LTER), South Shetland Islands (SSI) area (from the GAMLR expedition), and in krill fishery data from the Scotia Sea. The PM peaks shifted towards larger sizes in the SSI and fishery data, and the overall PM was high in SSI (Fig. 1).

Fig. 2 shows proportions of juveniles within each size bin for the survey areas. The size at which most of the juvenile krill turn into subadults differed between the survey areas. In all survey areas, all or most of the individuals were subadults or adults once they had reached $40 \mathrm{~mm}$. In the 35 to $40 \mathrm{~mm}$ size range, the proportion of juveniles varied between surveys, ranging from 0 to 0.2 , with the majority of observations being $<0.1$. Size bins between 30 and $35 \mathrm{~mm}$ showed an increasing ratio of juveniles (up to $>0.7$ ) towards the lower end. Size distributions of juveniles in KAOS, Palmer LTER, and SSI tended to show a broader range towards the larger size classes compared to BROKE, KACTAS, and fishery samples. Overall, the apparent PM calculated for size ranges $<35 \mathrm{~mm}$ may be misleading, since they were not categorized into gender. The size range between 35 and $40 \mathrm{~mm}$ may contain juveniles, because the proportions of juveniles observed in each size bin were mostly $<0.1$, but the potential bias can generally be considered to be $<10 \%$; this should not greatly affect the general trend in PM

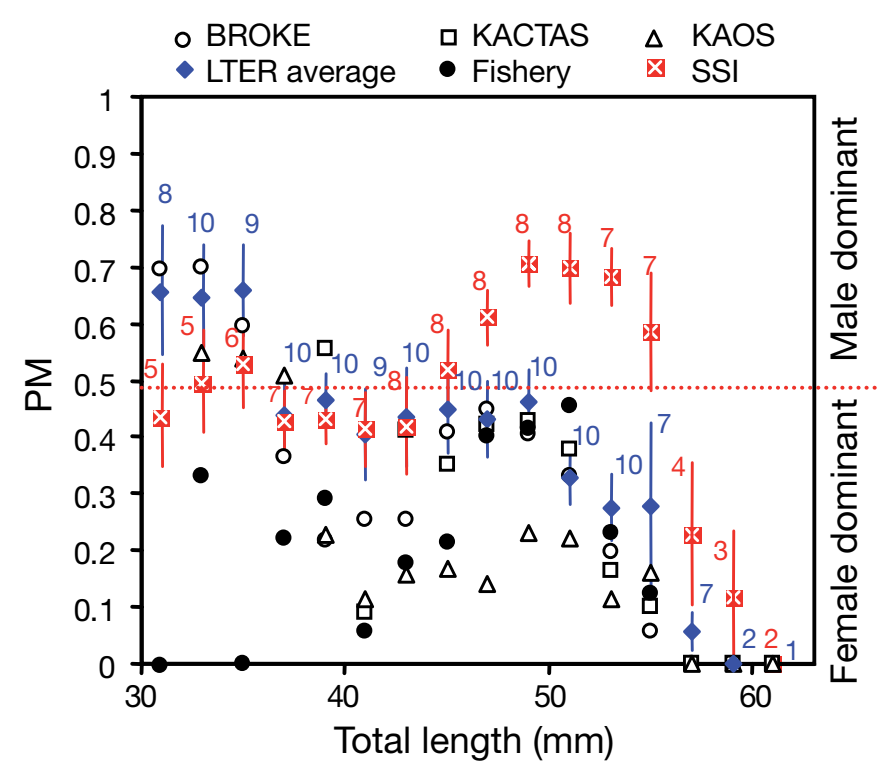

Fig. 1. Euphausia superba. Sex ratio (proportion of males, PM) from different cruises in the Indian Ocean sector (BROKE, KACTAS, KAOS; see 'Materials and methods-Surveys'); West Antarctic Peninsula area (Palmer LTER) (mean $\pm \mathrm{SE}$ ); South Shetland Islands area (SSI, from the German GAMLR Expedition) (mean $\pm \mathrm{SE})$; and the fishery from the Scotia Sea. Numerals at the top right or top left of each error bar denote $n$ (number of years) for Palmer LTER and SSI, respectively. Dotted line at 0.5 denotes equal numbers of males and females

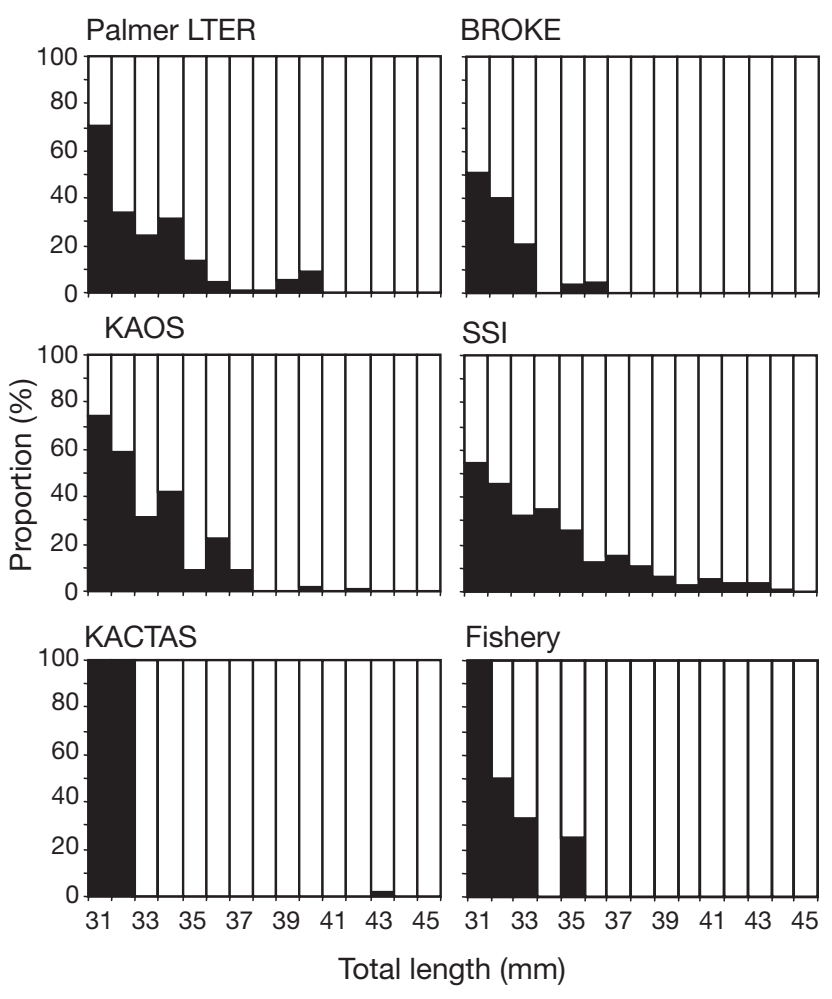

Fig. 2. Euphausia superba. Proportions of juveniles (black bars) within each $1 \mathrm{~mm}$ length bin between 30 and $45 \mathrm{~mm}$. White bars: subadults and adults 
across length classes. Therefore, we consider the trends in $\mathrm{PM}>35 \mathrm{~mm}$ to be appropriate for discussion.

\section{Interannual trends of recruitment and PM}

Fig. 3 shows interannual variation of PM in scientific net samples and in penguin diet samples, plotted together with recruitment indices in each area. The PM values of krill scientific net surveys in the Antarctic Peninsula region observed during Palmer LTER (1993 to 2003) were related to recruitment indices: a higher PM tends to be associated with good recruitment and a low PM follows poor recruitment (Fig. 3a). Krill in penguin diets in the South Shetland Islands also showed marked decrease in PM during the period of low recruitment (Fig. 3b), which is the same trend observed in scientific net samples (Fig. 3a).

\section{a Net sample (LTER region)}

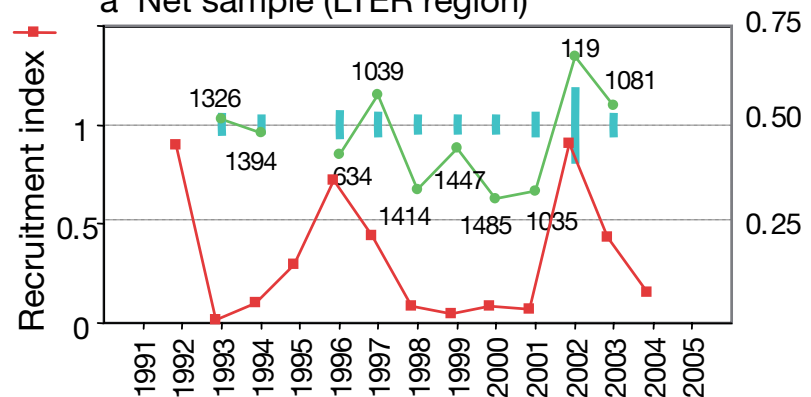

\section{b Penguin Diet (South Shetland)}

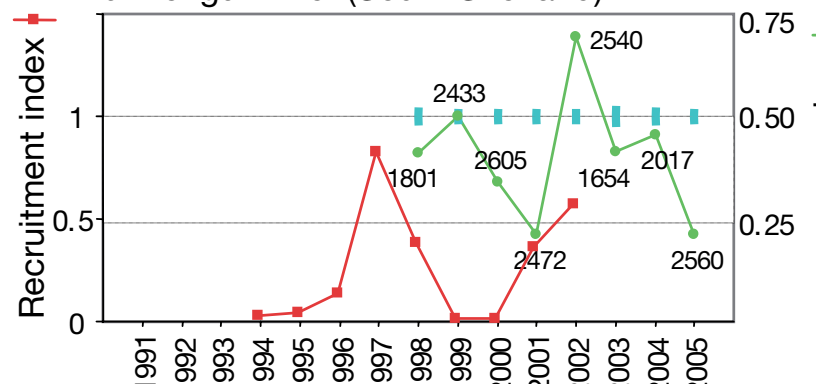

Field Season

Fig. 3. Euphausia superba. Proportion of males and recruitment index series from: (a) net samples, Palmer LTER site (Antarctic Peninsula area) and (b) krill samples from penguin diet, South Shetland Islands. Recruitment series of the Palmer LTER site $\left(\operatorname{Rec}_{1}\right.$ data for 1991-2001: Quetin \& Ross 2003; 2002-2003: Ducklow et al. unpubl. data) and Elephant Island area $\left(\mathrm{ReC}_{2}\right.$ data, Siegel et al. 2002) were plotted for the Palmer LTER site and South Shetland Island area, respectively, and adjusted to each field season. Vertical bars (I): 95\% CIs of simulated proportions of males comprised of random samples drawn from the binomial distribution, with the mean equal to 0.5 and sample size equal to the no. of ind. in our dataset (Wilson \& Hardy 2002). Numerals associated with the sex ratio symbols: no. of ind. (n)

\section{Model simulation}

Growth parameters

Fig. 4 shows sizes of male and female krill for the end of each growth season as estimated from Eq. (1) and assuming a growth period each year as indicated in Table 2 and in fitted VB growth models. Since krill sized above Age 3 males and Age 4 females were outside the range of our size-growth function (Table 2), VB growth curves were fitted to Age 1 to 3 males and Age 1 to 4 females. The estimated values for the parameters are listed in Table 3. From Fig. 4 and Table 3 it was determined that the model with common $L_{\infty}$ and $t_{0}$ parameters and the sex-specific $\kappa$ parameter, the $\operatorname{VB}(s, \kappa)$ model, gave the most sensible results with the estimate of $L_{\infty}$ of $60.1 \mathrm{~mm}$ close to the value obtained by Rosenberg et al. (1986) and the Age 6+ estimate of length obtained for Scenario Ia of Candy \& Kawaguchi (2006). In contrast, the malespecific estimate of $L_{\infty}$ in the $\operatorname{VB}\left(s, L_{\infty}, \kappa, t_{0}\right)$ model was unrealistic at $84.4 \mathrm{~mm}$, while the model $\mathrm{VB}(\mathrm{M}+\mathrm{F})$ failed to discriminate between males and females in terms of the faster early growth of the males seen in Fig. 4.

\section{PM across krill size}

Fig. 5a shows LFD through output of model simulation assuming a constant mortality rate of $M=0.6$ for

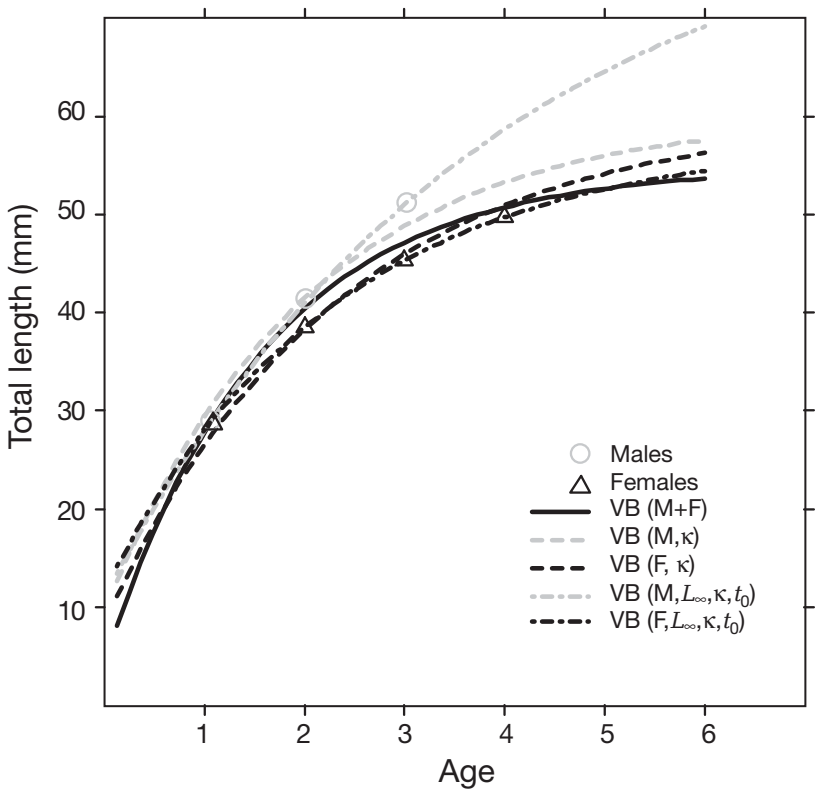

Fig. 4. Euphausia superba. Length of male and female krill for the end of each growth season as estimated from Eq. (1), assuming a growth period (December to April) each year as indicated in Table $2(\bigcirc$ : males; $\Delta$ : females), and fitted von Bertalanffy (VB) growth models (solid and dotted lines). Refer to Table 3 for parameters 
Table 3. Euphausia superba. Fitted von Bertalanffy (VB) growth models

\begin{tabular}{|c|c|c|c|c|c|c|}
\hline \multirow{2}{*}{ VB model } & \multirow{2}{*}{ Sex } & \multicolumn{5}{|c|}{ - VB parameters (SE) } \\
\hline & & $L_{\infty}$ & $\kappa$ & $t_{0}$ & Residual SE & Residual df \\
\hline $\mathrm{VB}(\mathrm{M}+\mathrm{F})$ & $\begin{array}{l}\text { Males } \\
\text { Females }\end{array}$ & $54.8(6.3)$ & $0.627(0.298)$ & $-0.13(0.41)$ & 2.401 & 4 \\
\hline $\begin{array}{l}\operatorname{VB}\left(\mathrm{M}, L_{\infty}, \kappa, t_{0}\right) \\
\operatorname{VB}\left(\mathrm{F}, L_{\infty}, \kappa, t_{0}\right)\end{array}$ & $\begin{array}{l}\text { Males } \\
\text { Females }\end{array}$ & $\begin{array}{l}84.4\left(3.7 \times 10^{-5}\right) \\
57.8\left(5.9 \times 10^{-6}\right)\end{array}$ & $\begin{array}{l}0.262\left(2.2 \times 10^{-7}\right) \\
0.435\left(1.5 \times 10^{-7}\right)\end{array}$ & $\begin{array}{l}-0.54\left(5.1 \times 10^{-7}\right) \\
-0.52\left(3.6 \times 10^{-7}\right)\end{array}$ & $1.02 \times 10^{-6}$ & 1 \\
\hline $\begin{array}{l}\operatorname{VB}(\mathrm{M}, \kappa) \\
\operatorname{VB}(\mathrm{F}, \kappa)\end{array}$ & $\begin{array}{c}\text { Males } \\
\text { Females }\end{array}$ & $60.1(9.7)$ & $\begin{array}{l}0.498(0.261) \\
0.431(0.218)\end{array}$ & $-0.35(0.45)$ & 1.921 & 3 \\
\hline
\end{tabular}

both males and females, with a SD of 3.0 for the normal distribution of length for each age class. Its PM across length exhibited a wavy pattern showing peaks centered at 32 and $43 \mathrm{~mm}$, with a trough in between and centered at $36 \mathrm{~mm}$ (Fig. 5b). From $47 \mathrm{~mm}$ onwards it showed a gradual increase (Fig. 5b).

\section{Effects of parameter variation on simulation outputs}

Lifespan of males. Fig. 6 shows trends in PM across length bins when a different lifespan was assumed for males (i.e. assuming zero survivals after lifespan)
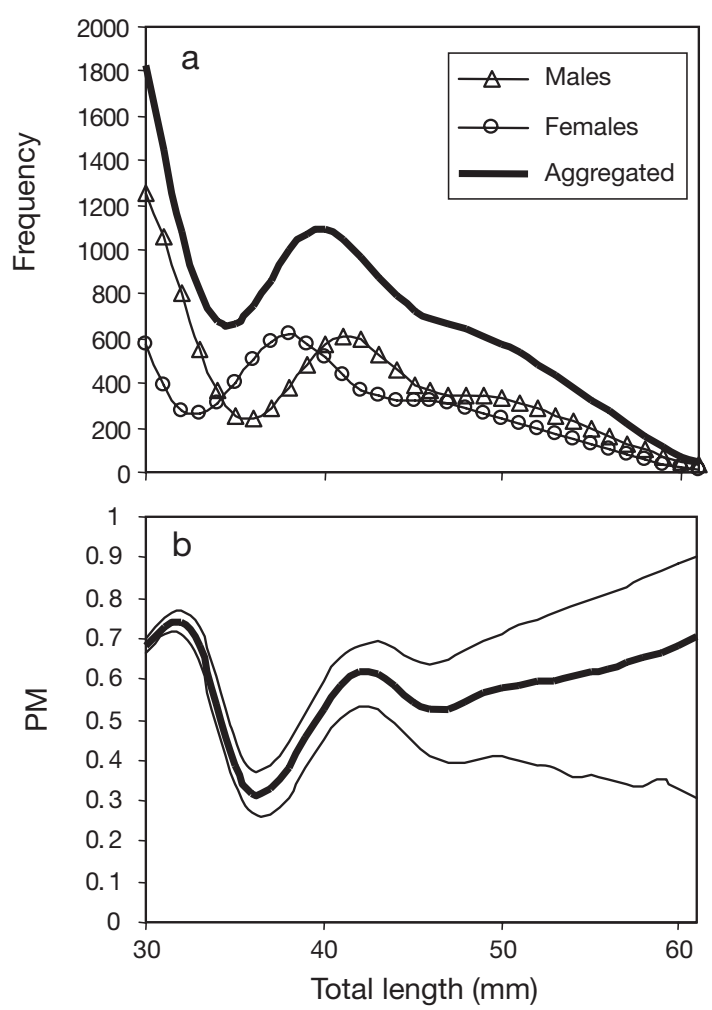

Fig. 5. Euphausia superba. (a) Length-frequency distribution, and (b) proportion of males (PM) from the output of model simulations assuming a constant mortality rate of $M=0.6$ for both males and females, with a SD of 3.0 for the normal distribution of length for each age class (data [for b] are mean $\pm 95 \% \mathrm{CI}$ ) compared to females. As the male lifespan shortens from 7 to $5 \mathrm{yr}$, only slight changes in the trend $>51 \mathrm{~mm}$ were observed. However, when male lifespan was set to 3 or $4 \mathrm{yr}, \mathrm{PM}>50 \mathrm{~mm}$ showed a declining trend. When male lifespan was set to $2 \mathrm{yr}$, the peak at $50 \mathrm{~mm}$ was lost and showed an almost steady decreasing trend $>43 \mathrm{~mm}$. A male lifespan of 3 to $4 \mathrm{yr}$ seemed to best explain the peak around $50 \mathrm{~mm}$ generally observed from the field data (Fig. 1).

Differential mortality rates between sexes. Fig. 7a shows changes in patterns of PM across size with varying male mortality rates assuming a lifespan of 3 yr for males. Unlike assuming constant mortality across sexes, the PM showed decreasing trends towards the higher end of the size range, regardless of male mortality. As the male mortality rate increased (0.6 to 1.2 ) — while female mortality was fixed (0.8) - the overall offset of PM values between 35 and $56 \mathrm{~mm}$ decreased. However, the general wavy pattern was maintained.

Fig. $7 \mathrm{~b}$ shows changes in patterns of PM across size with female mortality rates varying from 0.6 to 1.2 , male mortality fixed to 0.8 , and an assumed male lifespan of $3 \mathrm{yr}$. As the female mortality rate increased in relation to the male mortality rate, although the general wavy pattern was maintained, PM values between 35 and $56 \mathrm{~mm}$ generally increased; this was most pronounced around the size of $50 \mathrm{~mm}$.

Fig. 8 shows the mean trend of PM across length bins with different mortality rates, with the MFMR ratio being fixed at 1.5. Upper and lower 95\% CIs are shown in Fig. 8 based on the 1000 replicates. In spite of the trends in LFD changes, the trends in the PM remained unchanged, while the widths of the CIs increased as the overall mortality rates increased.

\section{Mortality acceleration}

Fig. 9a shows how the degree of accelerated mortality towards the end of the lifespan of male krill affects the patterns of PM across length bins using Eq. (4), with $\lambda=0.5,1.0,1.5$, and 2.0 from Age 3 (i.e. $\mathrm{A}_{\lambda}=3$ ) and $M_{M}=M_{F}=0.6$. Setting $\lambda=0$ assumes no 


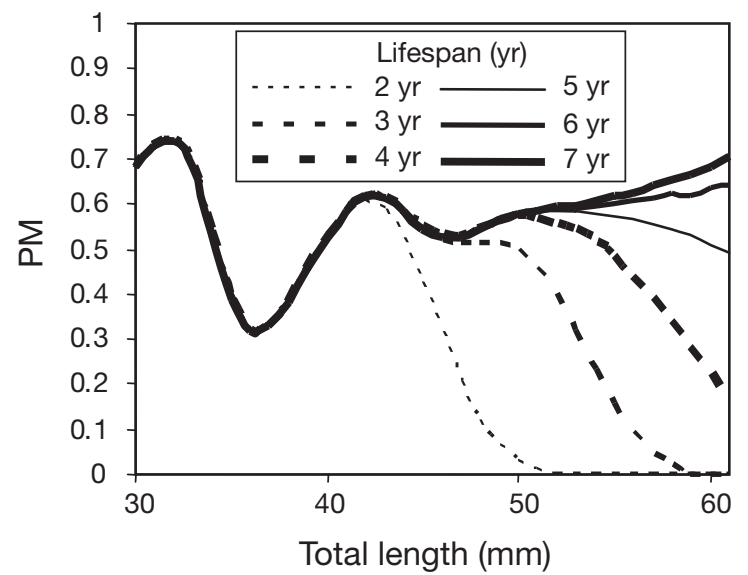

Fig. 6. Euphausia superba. Patterns of proportion of males (PM) under various lifespan assumptions. Other parameters: $M=0.6$ for both males and females, $\mathrm{SD}=3.0$

mortality acceleration after Age 3, which means the mortality will be kept constant up to Age 7 . As $\lambda$ increases, the degree of acceleration in mortality increases (Fig. 9b). The trend in PM $>50 \mathrm{~mm}$ turns into a decreasing trend from $\lambda=0.5$ and above. In the size range $>50 \mathrm{~mm}, \lambda=1.0$ to 2.0 resulted in a higher PM compared to patterns obtained when assuming a $3 \mathrm{yr}$ lifespan, but lower than that for an assumption of a $4 \mathrm{yr}$ lifespan (Fig. 9a). Only a negligible proportion of the population survived above Age 3, when $\lambda=1.0$ or greater (Fig. 9b).

\section{SD of age groups}

Fig. 10 shows PM across age classes for different assumed SD of the set of normal distributions combined with accelerated mortality above Age 3, with $\lambda=1.5$. Under the assumptions that SD was constant across ages and that small SDs led to a more pronounced wavy pattern as the SD was increased to 4 and 5 , the peaks observed at 43 and $48 \mathrm{~mm}$ diminished and formed a single plateau-shaped broad peak at 42 to $48 \mathrm{~mm}$. When an increasing SD was assumed with increasing age (i.e. SD of 2.5, 3.0, 3.5, 4.0, 4.5, and 5.0 corresponding to Ages 1-6, respectively) (Fig. 10), the shapes of the peaks and gaps became increasingly broader towards the higher end of the size range.

\section{Model versus field observations}

Fig. 11 overlays simulation output, which matched general features observed through the field data obtained from Palmer LTER (Fig. 11a), SSI (Fig. 11b), BROKE (Fig. 11c), and the rest of the surveys (KAOS, KACTAS, and fishery; Fig. 11d). For Palmer LTER, SSI, and BROKE, mortality rates corresponding to MFMR ratios of 1.33, 0.75, and 1.33 (with $M_{F}=0.6,0.8$, and 0.6), respectively, were used with $A_{\lambda}=3$ (using an accelerated mortality model with $\lambda=1.5$ for Palmer LTER and SSI and $\lambda=2.0$ for BROKE), whereas, for the rest of surveys, assuming an MFMR ratio of 2.0 and $M_{F}=0.6$ - with $A_{\lambda}=$ $3(\lambda=1.5)$ - seemed to better fit the field observations.

In general, the height and the trends in the wavy patterns of PM from the field results were reproduced by the simulation model. In the Palmer LTER, most of the field-derived values were within the $95 \%$ CIs, showing reasonably good agreement. On the other hand, for SSI, 1 of the 2 peaks produced through the model simulation was not observed in the field.

\section{DISCUSSION}

\section{General model output patterns under varying parameters}

As demonstrated in the 'Results' section for Euphausia superba, the observed wavy trend of PM with length obtained with the simulation model is a result of the combined effects of differential growth rates and
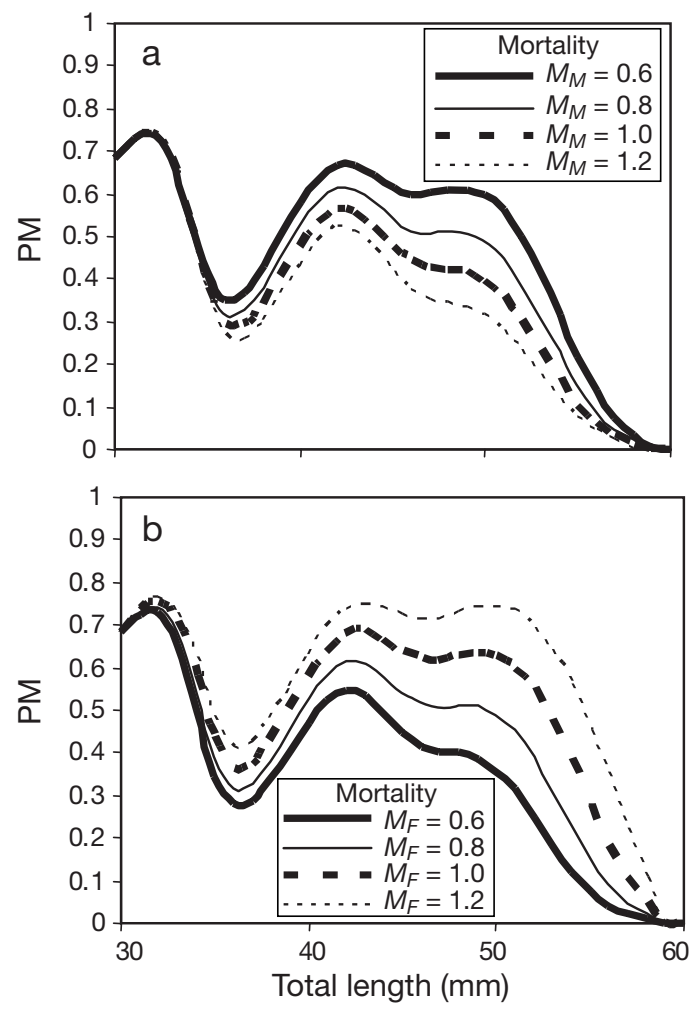

Fig. 7. Euphausia superba. Proportion of males (PM) with various mortality rates assuming a lifespan of $3 \mathrm{yr}$ for males. (a) Variable male mortality rates with fixed female mortality rate $\left(M_{F}=0.8\right)$. (b) Variable female mortality rates with fixed male mortality rate $\left(M_{M}=0.8\right)$. Other parameters: $\mathrm{SD}=3.0$ 

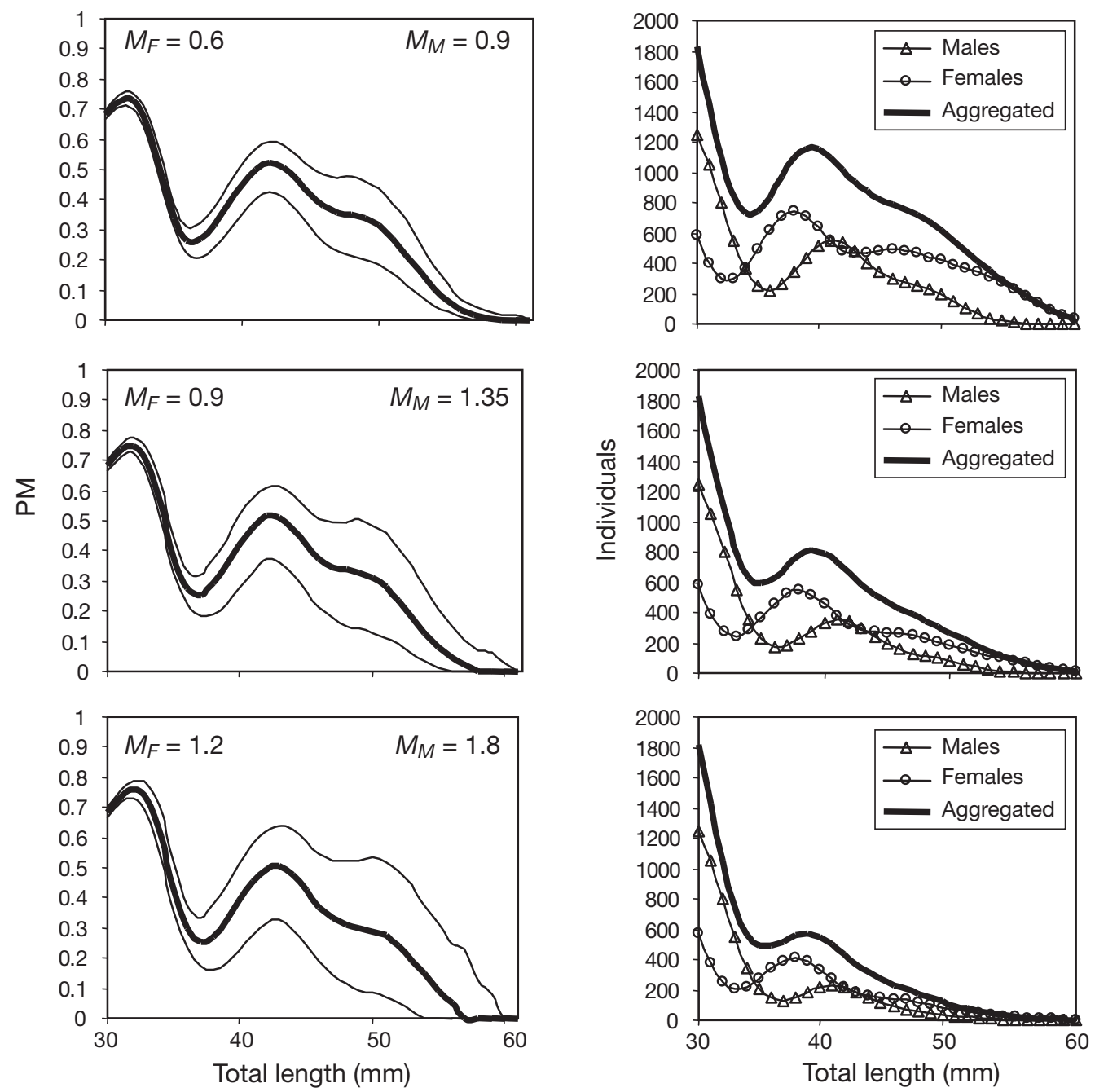

Fig. 8. Euphausia superba. Patterns of proportion of males (PM; left-hand panels) and LFDs (right-hand panels) with various mortality rates, but with the male-to-female mortality rate (MFMR) ratio fixed at 1.5. Other parameters: lifespan $=3 \mathrm{yr}, \mathrm{SD}=3.0$. Data are mean ( $\pm 95 \%$ CI for left-hand panels)

mortality rates between the sexes, the age composition of the population, the lifespan, the degree of mortality acceleration at the end of the lifespan, and the SD of length in each age class. Differences in growth rate cause a separation of the modal length in LFDs for each sex in the same age classes; thus, the PM differs between size bins (e.g. Fig. 5). Variations in mortality rates mainly affect the height of the PM pattern, but not the overall wavy pattern (Fig. 7). When the MFMR ratio is kept constant, even if the LFD dramatically changes, the pattern and the height of the waves are maintained (Fig. 8). The lifespan of males affects the trend towards the larger size classes (Fig. 6), and an assumption of a 3 to 4 yr male lifespan (Fig. 6), or accelerated mortality above Age 3 compared to the female lifespan of $7 \mathrm{yr}$ (Fig. 9) seemed to best reproduce the pattern observed from the field data. The SD of the size distribution in each age class also affected the observed trend (Fig. 10). Larger SD tend to broaden and flatten the peaks and gaps. Values of SD derived through mixture analysis of the krill LFD in the published literature vary between 1.5 and 6.4, with an average of between 2.9 and 3.3 across ages (Siegel 1987, Hosie 1988, Pakhomov 1995, Watkins 1999). Therefore, the assumption of 3 for the SD in our model seems to be reasonable.

\section{Lifespan}

Although the model simulation reproduced the main features of PM across size observed from the field surveys, there were also some discrepancies. None of the field data showed the distinct peak of PM at $42 \mathrm{~mm}$, which was observed in the model simulation (Fig. 11). Palmer LTER did not show a trough at $42 \mathrm{~mm}$, but still 
did not show a peak. One of the explanations for this is that the actual male growth rate up to Age 2 is higher than our estimated growth curve (higher $\mathrm{\kappa}$ ), so that the males reach larger sizes by the end of Age 2, resulting in the entire wavy pattern from the field being shifted towards the larger sizes. However, this explanation is unsatisfactory since the VB parameter in this study was derived from the results of instantaneous growth rate experiments, including those conducted during the BROKE survey (Kawaguchi et al. 2006), and it also seems difficult to envisage how males can reach a size of $50 \mathrm{~mm}$ in $2 \mathrm{yr}$. Another explanation for this is to assume that some portion of Age 2 males migrate out of the main survey area (horizontally and/or vertically), but migrate back into the area at Age 3, so that the field-derived PM lacks a $42 \mathrm{~mm}$ peak. Although this is rather speculative, it is quite likely, since geographical separation of distribution among different developmental stages is well known and documented, showing immature krill closer to the continent (e.g. Siegel 1987, 2005). Further, there is some evidence to support this suggestion; the Palmer LTER transects were located very close to the continent compared to those of the SSI and BROKE surveys, so that they covered most of the population, and the trough centered at $42 \mathrm{~mm}$ in the PM trend was not as pronounced as the valleys during SSI and BROKE.

KACTAS, KAOS and the Scotia Sea fishery showed more scattered plots (Fig. 11d) than the other surveys. This could be because each of these are from single years, especially for KACTAS and KAOS being local surveys, and it is possible that the LFD may represent only part of the population. Some of the high variability in these results is also explained by the small sample size, because of the smaller number of animals surviving towards the larger end of the size spectrum. The age composition of the population is another factor influencing the observed pattern. If the sample lacks an age class, then this propagates in the subsequent years' LFD (Reid et al. 1999). Therefore, the pattern may become irregular within the size range of the age class, because of small sample sizes around the size range of the missing age class (i.e. Age 2 in the KACTAS sample). Since the fishery data originate from a wide area of the Southwest Atlantic sector krill fishing ground (from the Antarctic Peninsula to South Georgia), encompassing large latitudinal differences, it is possible that the data consist of krill with various growth and mortality rates (Reid et al. 2002). This is also another reason why the fishery data did not show as clear a pattern as the PM values derived from long-term scientific surveys.

Overall, it appears that the pattern of PM across size is mainly dictated by the lifespan of males ( 3 to $4 \mathrm{yr}$ ) in relation to that of females ( $7 \mathrm{yr})$. From the results of our model simulation and the general field PM pattern, it is reasonable to suggest that male krill
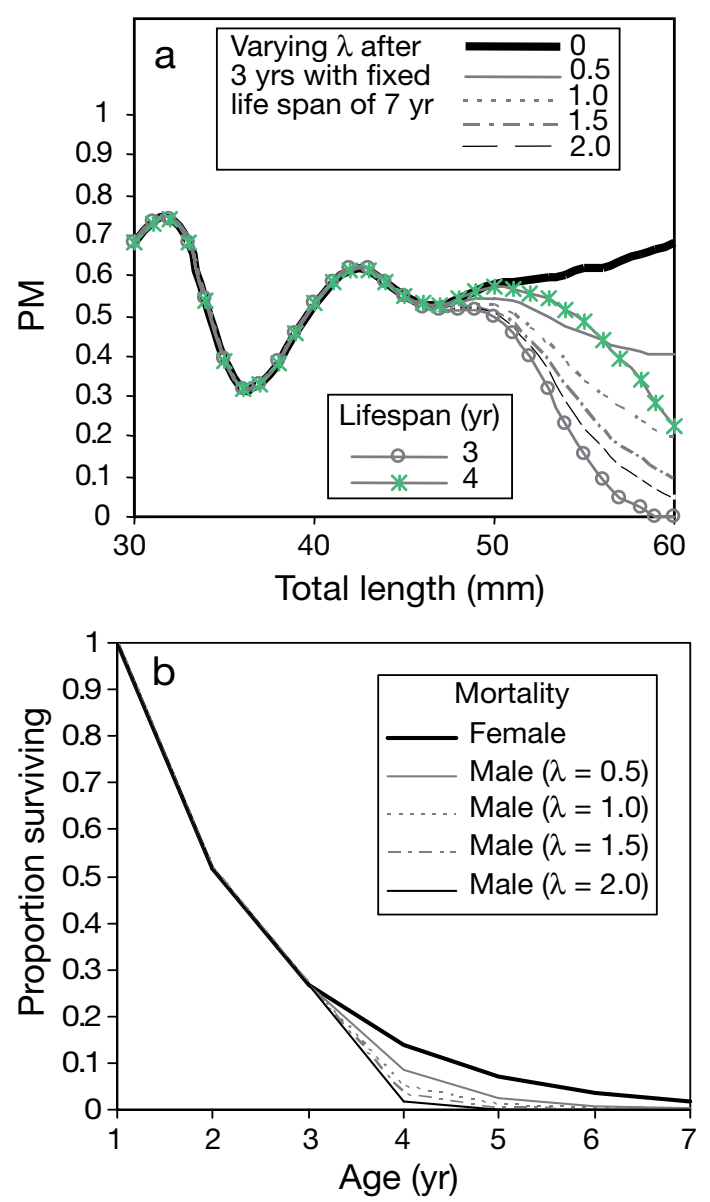

Fig. 9. Euphausia superba. Patterns of proportion of males (PM) assuming various degrees of mortality acceleration ( $\lambda$ ) after Age 3 comparing male lifespans of 3 and 4 yr: (a) PM across size and (b) proportions of population surviving at the end of each age class for the accelerated mortality model. Other parameters: $M=0.6$ for both males and females, $\mathrm{SD}=3.0$

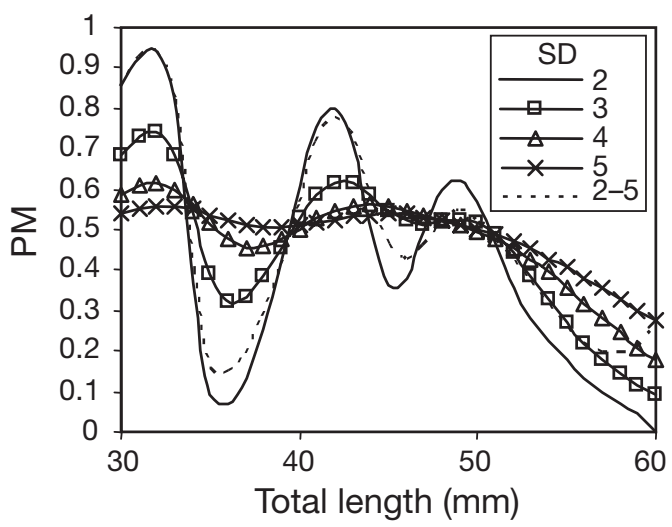

Fig 10. Euphausia superba. Proportion of males (PM) with different SDs of normal distributions assumed for age classes ( $\lambda=1.5$ above Age 3 ). Other parameters: $M=0.6$ for both males and females 

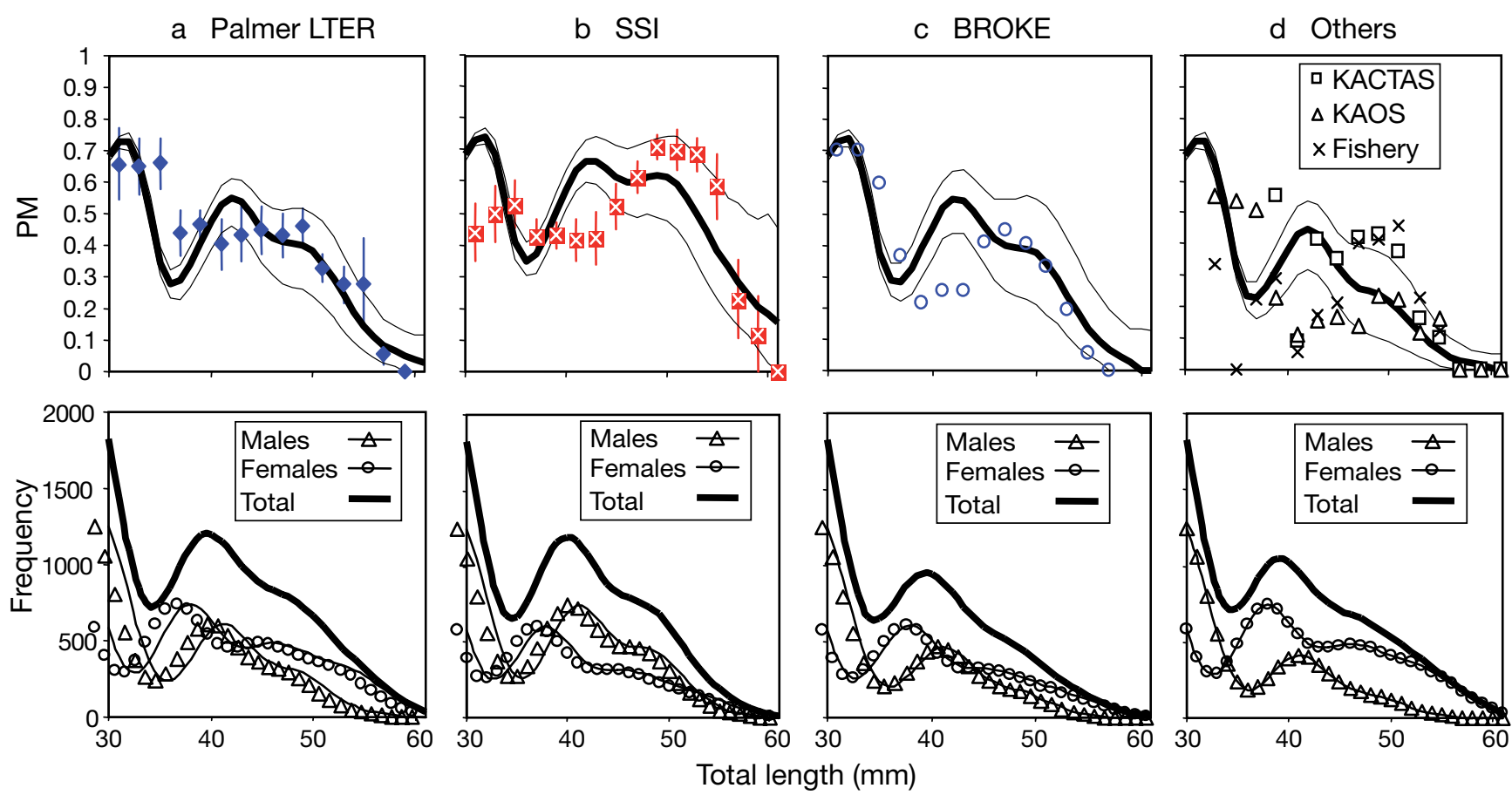

Fig. 11. Euphausia superba. Overlays of simulated mean PM (thin lines showing lower 5 and upper $95 \%$ simulation envelopes) on the field data (upper panels) and simulated length-frequency distributions (lower panels). (a) Palmer LTER, (b) SSI, (c) BROKE, and (d) the other surveys (KAOS, KACTAS, and fishery); for survey abbreviations, see 'Materials and methods - Surveys'. For (a) and (b) error bars $=\mathrm{SE}$

accelerate their mortality rate above Age 3, while females have a longer lifespan $(\sim 7 \mathrm{yr})$.

The shorter lifespan in males compared to that of females will result in a lower PM. Simply put, male krill grow faster, but die younger. A higher PM at the time of birth could compensate for the shorter lifespan, because more potential males are born and/or subadult males grow faster.

\section{Differential mortality rates between sexes}

Our study suggests MFMR ratio varies between regions. The lowest MFMR ratio was at SSI (0.75), followed by that at Palmer LTER and BROKE (1.33) and then at the rest of the surveys (2.0). What are the reasons for these differences? Predation pressure is considered one of the major causes of natural mortality. Tarling (2003) demonstrated that female North Atlantic krill Meganyctiphanes norvegica risk predation to increase their energy intake during the reproductive season by migrating closer to the surface, resulting in an increasing male ratio towards the end of each reproductive season. At the same time, males may be less able to survive longer term, because they have lower energy reserves and may not endure periods of starvation as well as females (Virtue et al. 1996, Cuzin-Roudy et al. 1999, Tarling 2003). If this theory also applies to Antarctic krill, then we would expect a higher MFMR ratio (i.e. males die off faster than females) where predation pressure is low, and, as predation pressure increases, we would expect a decrease in the MFMR ratio. Referring to the number of breeding colonies of major land-based krill predators such as penguins (Woehler 1993) and fur seals (Fischer \& Hureau 1985), we might expect higher predation pressure in the SSI compared to in the Palmer LTER. It is also generally accepted that the abundance of krill predators is greater in the Southwest Atlantic sector area compared to the rest of the Southern Ocean (e.g. Croxall et al. 1988). This can explain the regional differences in the MFMR ratio observed in our study. One exception is the high MFMR ratio (2.0) from the fishery data, which mainly operates in the Antarctic Peninsula area. The most likely explanation for this is, due to market preference for large gravid females, commercial vessels tend to aim for gravid females (Kawaguchi et al. 2005, Kawaguchi \& Nicol 2007), resulting in a sex ratio biased towards large females in their catch composition.

\section{Inter-annual trends of recruitment and PM and their implications}

Results of long-term monitoring programs undertaken in the Antarctic Peninsula area provide further evidence to support the concept of rapid growth and a 
shorter average lifespan in male krill. In most species the proportion of embryos that are males is 0.5 , and, if this deviates from equilibrium, natural selection tends to drive it back (Fisher 1930, Hamilton 1967); therefore, if this is the case for krill, then we would expect variation of the PM around a value of 0.5. However, the PM of krill in the Antarctic Peninsula region observed at the Palmer LTER (1993 to 2003) are related to recruitment indices: a higher PM with a value significantly $>0.5$ tends to be associated with good recruitment, and a low PM follows poor recruitment (Fig. 3a). Furthermore, data obtained from krill in penguin diets in the South Shetland Islands also showed the same trend (i.e. PM decreases markedly during periods of low recruitment; Fig. 3b). This pattern of a high PM following approximately 2 yr of high recruitment and a low PM following a series of bad recruitment years can be explained by the shorter lifespan of males. It is also noteworthy that inter-annual trends in the proportion of male krill were similar between penguin diets in the South Shetland Islands and net samples from the Palmer LTER site, which was located between 300 and $1000 \mathrm{~km}$ away. This supports previously published findings of large-scale synchronous effects on krill recruitment (Siegel et al. 2003). As the population ages during periods of low recruitmentand thus little input of new males - the population becomes dominated by the longer living females. With a burst of good recruitment, combined with a higher proportion of males than females at birth, the ratio becomes skewed towards males as seen in Fig. 3.

Levels of differential mortality rates between sexes may also have an effect on the inter-annual variation of $\mathrm{PM}$. It is envisaged that the overall PM might be higher under high predation pressure and vice versa due to possible selective predation on females over males (as discussed in the previous section). The general rules in PM variation should remain the same (i.e. high PM should be observed after a strong recruitment event; later females should dominate after a series of poor recruitments). Although not available in the present study, it would be interesting to examine the interannual series of PM values in other regions with different levels of predation pressure.

The shorter lifespan of males means that several years of recruitment failure may be catastrophic to population survival, due to shortage of males contributing to reproduction. Winter sea-ice is regarded as a habitat essential to the survival of recruits, an important driver of the spring phytoplankton bloom boosting the fecundity of gravid females (Kawaguchi et al. 2007), as well as delaying salp blooms, which are thought to be a competitor for the food source (Siegel \& Loeb 1995). Cold winters with extensive sea-ice cover have decreased from 4 out of 5 yr during the middle of this century to 1 or 2 out of 5 yr since the 1970s (Fraser et al. 1992, Fraser \& Trivelpiece 1996), and reported declines in krill density and possible recruitment failures in the South Atlantic have been associated with reductions in sea-ice area (e.g. Siegel \& Loeb 1995, Loeb et al. 1997, Atkinson et al. 2004). Accelerated mortality in above Age 3 males in our study means that if the winter sea-ice condition is poor for $>3$ consecutive years, then there will be a major reduction in surviving productive males and restoration of the population will be more difficult. Given the information on the sea-ice condition (1 to 2 out of $5 \mathrm{yr}$ in the Southwest Atlantic sector), it may be possible that krill in this area are barely maintaining their population, and any further reduction in the frequency of good winter sea-ice coverage may have a major negative impact on the regional krill population, and, therefore, as the keystone species, this effect may directly impact the regional ecosystem.

Ecosystem management of the Southern Ocean is overseen by CCAMLR, applying a precautionary approach, and requires a fundamental knowledge of the krill life cycle and information on their population dynamics (i.e. growth rates, mortality, recruitment, and lifespan). Our results suggest that the simple use of LFDs to determine age and recruitment, as is currently used in krill management, is problematic, particularly for Age Classes 2 and older if males and females are pooled.

Acknowledgements. We thank Prof. M. Mangel (UCSC, California) for valuable comments on an earlier draft of the manuscript. Critical comments by the 3 anonymous reviewers greatly improved the manuscript. Data from the Palmer LTER program was based on support from the National Science Foundation, Office of Polar Programs, under award nos. OPP9011927 and OPP-9632763, and OPP-0217282, the Regents of the University of California, the University of California at Santa Barbara, and the Marine Science Institute, UCSB. This is Palmer LTER contribution no. 0290

\section{LITERATURE CITED}

Atkinson A, Siegel V, Pakhomov E, Rothery P (2004) Longterm decline in krill stock and increase in salps within the Southern Ocean. Nature 432:100-103

Baker AC, Clarke MR, Harris MJ (1973) The N.I.O. combination net (RMT 1+8) and further developments of Rectangular Midwater Trawls. J Mar Biol Assoc UK 53:176-184

Bargmann HE (1945) The development and life-history of adolescent and adult krill, Euphausia superba. Discovery Rep 23:103-176

Candy SG, Kawaguchi S (2006) Modelling growth of Antarctic krill. II. Novel approach to describing the growth trajectory. Mar Ecol Prog Ser 306:17-30

CCAMLR (Commission for the Conservation of Antarctic Marine Living Resources) (2003) CCAMLR ecosystem monitoring program: standard methods for monitoring studies. CCAMLR, Hobart

Croxall JP, McCann TS, Prince PA, Rothery P (1988) Reproduc- 
tive performance of seabirds and seals at South Georgia and Signy Island, 1976-1987: implications for Southern Ocean monitoring studies. In: Sahrhage D (ed) Antarctic Ocean and resources variability. Springer, Berlin, p 261-285

Cuzin-Roudy J, Albessard E, Virtue P, Mayzaud P (1999) The scheduling of spawning in relation to the moult cycle in Northern krill (Crustacea: Euphausiacea): a strategy for allocating lipids to reproduction. Invert Reprod Dev 36: 163-170

de la Mare WK (1994) Modelling krill recruitment. CCAMLR Sci 1:49-54

Fischer W, Hureau JC (eds) (1985) FAO species identification sheets for fishery purposes, Vol 2. Food and Agriculture Organization of the United Nations, Rome

Fisher RA (1930) The genetical theory of natural selection. Clarendon Press, Oxford

Fraser WR, Trivelpiece WZ (1996) Factors controlling the distribution of seabirds: winter-summer heterogeneity in the distribution of Adélie penguin populations. In: Ross RM, Hofmann EE, Quetin LB (eds) Foundations for ecological research west of the Antarctic Peninsula. Am Geophys Union Res Ser 70:257-272

Fraser WR, Trivelpiece WZ, Ainely DG, Trivelpiece SG (1992) Increases in Antarctic penguin populations: reduced competition with whales or a loss of sea ice due to global waming? Polar Biol 11:525-531

Hamilton WD (1967) Extraordinary sex ratios. Science 156: $477-488$

Hill HJ (1990) A new method for the measurement of Antarctic krill Euphausia superba Dana from predator food samples. Polar Biol 10:317-320

Hosie GW, Ikeda T, Stolp M (1988) Distribution, abundance and population structure of the Antarctic krill (Euphausia superba Dana) in the Prydz Bay region, Antarctica. Polar Biol 8:213-224

Kawaguchi S, Nicol S (2007) Learning about Antarctic krill from the fishery. Antarct Sci 19:219-230

Kawaguchi S, Candy SG, Nicol S, Taki K, Naganobu M (2005) Analysis of trends in Japanese krill fishery CPUE data, and its possible use as a krill abundance index. CCAMLR Sci 12:1-28

Kawaguchi S, Candy SG, King R, Naganobu M, Nicol S (2006) Modelling growth of Antarctic krill. I. Growth trends with sex, length, season, and region. Mar Ecol Prog Ser 306:1-15

Kawaguchi S, Yoshida T, Finley L, Cramp P, Nicol S (2007) The krill maturity cycle: a conceptual model of the seasonal cycle in Antarctic krill. Polar Biol 30:689-698, doi: 10.1007/s00300-006-0226-2

Loeb V, Siegel V, Holm-Hansen O, Hewitt R, Fraser W, Trivelpiece W, Trivelpiece S (1997) Effects of sea-ice extent and krill or salp dominance on the Antarctic food web. Nature 387:897-900

Makarov RR, Denys CJ (1980) Stages of sexual maturity of Euphausia superba Dana. BIOMASS Handbook no. 8

Marr JWS (1962) The natural history and geography of the Antarctic krill (Euphausia superba Dana). Disc Rep 32: 33-464

Morris DJ, Watkins JL, Ricketts C, Buchholz F, Priddle J (1988) An assessment of the merits of length and weight measurements of Antarctic krill Euphausia superba. Br Antarct Surv Bull 79:27-50

Nicol S (2000) Understanding krill growth and aging: the contribution of experimental studies. Can J Aquat Sci 57(Suppl 3):168-177

Nicol S, Endo Y (1999) Krill fisheries: development, management and ecosystem implications. Aquat Living Resour 12: $105-120$

Editorial responsibility: Otto Kinne (Editor in Chief),

Oldendorf/Luhe, Germany
Nicol S, Pauly T, Bindoff NL, Wright S, Thiele D, Hosie GW, Strutton PG, Woehler E (2000) Ocean circulation off east Antarctica affects ecosystem structure and sea-ice extent. Nature 406:504-507

Pakhomov EA (1995) Demographic studies of Antarctic krill (Euphausia superba) in the Cooperation and Cosmonaut Seas (Indian sector of the Southern Ocean). Mar Ecol Prog Ser 119:45-61

Quetin LB, Ross RM (2003) Episodic recruitment in Antarctic krill Euphausia superba in the Palmer LTER study region. Mar Ecol Prog Ser 259:185-200

Reid K, Barlow KE, Croxall JP, Taylor RI (1999) Predicting changes in the Antarctic krill, Euphausia superba, population at South Georgia. Mar Biol 135:647-652

Reid K, Murphy EJ, Loeb V, Hewitt RP (2002) Krill population dynamics in the Scotia Sea: variability in growth and mortality within a single population. J Mar Syst 36:1-10

Rosenberg AA, Beddington JR, Basson M (1986) Growth and longevity of krill during the first decade of pelagic whaling. Nature 324:152-154

Siegel V (1987) Age and growth of Antarctic Euphausiacea (Crustacea) under natural conditions. Mar Biol 96:483-495

Siegel V (2005) Distribution and population dynamics of Euphausia superba: summary of recent findings. Polar Biol 29:1-22

Siegel V, Loeb V (1994) Length and age at maturity of Antarctic krill. Antarct Sci 6:479-482

Siegel V, Loeb V (1995) Recruitment of Antarctic krill Euphausia superba and possible causes for its variability. Mar Ecol Prog Ser 123:45-56

Siegel V, Nicol S (2000) Population parameters. In: Everson I (ed) Krill: biology ecology and fisheries. Blackwell, London, p 103-149

Siegel V, Bergstrom B, Muhlenhardt-Siegel U, Thomasson M (2002) Demography of krill in the Elephant Island area during summer 2001 and its significance for stock recruitment. Antarct Sci 12:162-170

Siegel V, Ross RM, Quetin LB (2003) Krill (Euphausia superba) recruitment indices from the western Antarctic Peninsula: Are they representative of larger regions? Polar Biol 26: 672-679

Smith RC, Baker KS, Fraser WR, Hofmann EE and 6 others (1995) The Palmer LTER: a long-term ecological research program at Palmer Station, Antarctica. Oceanography 8: 77-86

Tarling GA (2003) Sex-dependent diel vertical migration in northern krill Meganyctiphanes norvegica and its consequences for population dynamics. Mar Ecol Prog Ser 260: 173-188

Virtue P, Nichols PD, Nicol S, Hosie G (1996) Reproductive trade-off in male Antarctic krill, Euphausia superba. Mar Biol 126:521-527

Watkins JL (1999) A composite recruitment index to describe interannual changes in the population structure of Antarctic krill at South Georgia. CCAMLR Sci 6:71-84

Watkins JL, Hewitt R, Naganobu M, Sushin V (2004) The CCAMLR 2000 survey: a multinational, multi-ship biological oceanography survey of the Atlantic sector of the Southern Ocean. Deep-Sea Res II 51:1205-1456

Wilson K, Hardy ICW (2002) Statistical analysis of sex ratios: an introduction. In: Hardy ICW (ed) Sex ratios: concepts and research methods. Cambridge University Press, Cambridge, $\mathrm{p} 49-92$

Woehler EJ (1993) The distribution and abundance of Antarctic and Subantarctic penguins. BIOMASS Scientific Series/SCAR Bird Biology Subcommittee, SCAR, Cambridge

Submitted: August 17, 2006; Accepted: February 28, 2007

Proofs received from author(s): August 24, 2007 